\title{
1. The everyday making of EU foreign and security policy
}

\author{
Niklas Bremberg, August Danielson, Elsa \\ Hedling and Anna Michalski
}

\section{THE EU'S RESPONSE TO INTERNAL AND EXTERNAL CHALLENGES}

At a time of profound transformation of the international system, the liberal world order is seemingly giving way to a new power-based order. Amidst rising right-wing populism in the Western world, a global backsliding of democracy, and blatant breaches of liberal norms, such as human rights and the rule of law, the role of the European Union (EU) as an international actor is under pressure. Certain state actors are questioning not only the EU's capacity to act on the international scene and decisively handle major international crises, but also its ability to take actions from within when member states do not fully comply with its values and principles. The contestation is epitomized by the deep fault lines among the EU member states concerning threats from Russia, China and Turkey, and the constant disruption by a handful of member states of the EU's efforts to uphold principles of human rights in international forums. Despite these challenges, which regularly prompt pundits to herald the breakdown of European diplomacy, the EU continues to shape the global agenda in international development and climate change mitigation, forge relations with third countries through international agreements and strategic partnerships, uphold international rules and norms, and contribute to global security. Clearly, here lies a paradox that has not yet been resolved: How can EU foreign policy continue to be shaped and carried out, day after day, despite seemingly growing disagreement among member states and in an increasingly hostile international context? This paradox gives rise to a number of questions. What diplomatic practices allow for the management of internal contestation? What role does socialization and the learning of common practices play in upholding the cohesiveness and sense of purpose among European diplomats and civil servants? Despite contestation, or perhaps as a result of it, are there communities of practice emerging in EU foreign and security policy? 
The focus of this book is on the everyday practices of foreign policy-making in the EU. Specifically, this book focuses on the individuals who through their daily interactions forge concrete policy positions and enact the EU's international role. By putting everyday practices in focus, we aim to reveal a number of aspects of EU foreign policy-making and the special type of diplomatic coordination practised in different bodies and at different levels of EU policy-making. Much contemporary scholarship on European foreign policy has concentrated on the institutionalization of the Common Foreign and Security Policy (CFSP), the allocation of resources and policy competences to the European External Action Service (EEAS), and the action, or lack thereof, of the EU in international forums and international security crises. We know much less about the formal and informal practices of European diplomacy that have developed over the last two decades. We have only scant understanding of the way in which contestation is managed in bodies in which EU foreign and security policy is made, coordinated and implemented. To this end, we aim to reveal how communities of practice are forged and how they sustain their efficiency and working environments through formal and informal rules and norms of behaviour. Despite the contestation between member states, the practitioners of the CFSP are able to 'keep the ball rolling' by upholding group norms of appropriate behaviour, primarily through the diffusion of practical knowledge regarding what it means to be a good EU diplomat and official. These practices also develop through a strong willingness by the participants to make European foreign policy work, sometimes because there is a realization that a certain way of working does not function and needs to change, and sometimes through a more gradual, non-reflective process of simply trying to increase the efficiency of the group. Clearly, the evolving institutional setting of EU foreign and security policy offers a less constraining bureaucratic environment for the participants who can and do take the initiative to find ways to make the EU work by developing new practices. In many ways, it is in the intersection of an increasingly uncertain, albeit demanding, international context and a still malleable institutional setting that there is the most room to develop new diplomatic practices.

By studying the concrete practices of European foreign policy, which over time have become commonplace, we can explicate the nature of the community of diplomatic practice that has emerged in the EU. Although EU foreign policy is beset by a deep uncertainty about the orientation and shape of concrete policy, grounded in the disagreement among member state governments about the goals and remit of the CFSP, we contend that the evolving European community of diplomatic practice is geared towards problem-solving by overcoming dissent and thereby finding ways to move forward. These practices are self-generating and are constantly evolving through processes of self-evaluation and adherence to informal norms of behaviour, which 
contribute to the ability of the EU diplomatic community to manage internal contention and dissent.

In the parlance of traditional integration theories, the propensity of European policy-makers to overcome disagreements and find compromises has been understood as constituting the engine of deepening integration. However, these perspectives have rarely incorporated the daily actions of European diplomats and civil servants as part of the explanation for how the engine of integration is moving forward. In this book, we present a novel theoretical take on the specific blend of reflexive (self-conscious) and non-reflexive (commonsensical) interaction in the European diplomatic community. This perspective combines insights from practice approaches, which highlight the importance of background knowledge in communities of practitioners, with insights from socialization theory, which emphasizes a plurality of processes through which individuals adopt the norms and rules prescribing how to interact in order to shape and carry out a group's goals, such as EU foreign policy. A key argument of this book is that the unique combination of the daily grind of policy-making based on reiterative interaction in relatively unfinished politico-institutional structures provides aspirational goals, bureaucratic procedures and physical venues for policy-makers, as well as opportunities for practical change through creativity and flexibility. Together, this has shaped an environment where the European diplomatic community not only coordinates national foreign policy, but also handles dissent among member states, with the express aim of producing tangible diplomatic actions and substantive foreign policy.

\section{PRACTICAL COOPERATION AND SECURITY CRISES AS TRIGGERS FOR INSTITUTIONAL REFORM}

The origins of modern-day practices in EU foreign and security policy can be traced to the development of the CFSP, which was formally included in the policy remit of the EU in 1993 as a result of the ratification of the Maastricht Treaty. However, cooperation among EU member states in international affairs predates the Maastricht Treaty by several decades, as European leaders created a semi-formal consultation process on foreign policy issues in the early 1970s (see Chapter 2). In addition, the European Political Cooperation (EPC) was set up to proceed in parallel to, but independently of, the European Community, as integration in the realm of foreign policy was considered to be going too far in terms of relinquishing state sovereignty. Despite the modest start of the EPC, national diplomatic corps gained experience by working together, especially by learning about their respective traditions, world views and strategic interests as well as by instituting processes of consultation and cooperation. Despite some antagonism on behalf of the national diplomatic services vis-à-vis the forays of the EU institutions into foreign affairs, the latter's competence in 
areas such as trade and international development gradually increased and gained recognition.

The impetus for closer cooperation in foreign and security policy came with the geopolitical shift at the end of the Cold War and the heightened role of the EU in a peaceful unification of Europe. In the early 1990s, however, the CFSP encountered some considerable setbacks, including the genocide in Rwanda and the wars in the former Yugoslavia, where the EU proved unable to act as a security provider. Furthermore, the member states' reluctance to let go of national prerogatives resulted in rather haphazard common policy positions. In view of these problems, the EU member states agreed to strengthen the CFSP through a number of institutional reforms enshrined in the 2009 Lisbon Treaty. These reforms led to the creation of the EEAS and a strengthening of the office of the High Representative (HR) for Foreign Affairs and Security Policy. The aim of these reforms was to strengthen the EU's role as a post-sovereign international actor and, although not explicitly stated, to uphold its self-image as a force for good in the world.

Nonetheless, the EU's ability to formulate a common foreign policy has been challenged in the last decade. In some areas, such as the international climate agenda, the Iran Nuclear Agreement, international trade, and the Brexit negotiations with the United Kingdom, the EU member states have forged a common stance, along with the agreement to strengthen its strategic autonomy through the adoption of the Permanent Structured Cooperation (PESCO). In other areas, however, chiefly human rights and rule of law, the EU has been unable to adopt a unified stance, primarily due to a few member states blocking common positions on issues related to the EU's constitutive norms and values. Moreover, the EU member states' continued reluctance to project hard power under the EU flag through military-backed Common Security and Defence Policy (CSDP) operations has hampered the EU's actorness in peacekeeping and military crisis management (see Chapter 9). In part, this incapacity can be explained by diverging threat assessments, including the geographical proximity of Russia and Northern Africa for the member states in Eastern and Southern Europe, respectively. However, this incapacity is also related to entrenched national strategic cultures that impede the formulation of an effective European security doctrine. Dissent in European foreign policy is not a new phenomenon, but in recent years the contestation that is hampering the CFSP has grown more consequential, as the internal and external expectations have risen while the foreign policy remit of the EU has widened. Nonetheless, the member states that block a common approach in the areas mentioned above do so seemingly without regretting the damage it does to the EU's self-understanding and standing in the world.

In practice, therefore, some EU member states' lack of willingness to comply with common standpoints or resolve differences in foreign policy 
preferences have thwarted the EU's attempts to adopt a consistent approach to issues related to human rights, which lie close to its international identity. In addition, the EU's rather fragmented positions on how to best manage relations with major powers such as Russia, the United States (US) and China has weakened its standing as a global actor. However, despite the inability of the EU to consistently forge a united approach, the CFSP still continues to produce policy output by negotiating international treaties, maintaining strategic partnerships with third countries, adopting sanctions, distributing foreign aid, ensuring maritime security, assisting security sector reform in third countries, and carrying out border monitoring missions. These are just a few of the EU's growing external activities. This complex state of affairs permeates the day-to-day work of the individuals who produce and enact the CFSP, either by setting the agenda and coordinating concrete policy stances in Brussels, or by implementing these policies in CSDP operations, international organizations or third country capitals. Nonetheless, the disparity persists between certain EU member states' policy positions. Therefore, contestation among EU member states needs to be managed on a daily basis, which has become part of the practices and patterns of interaction among the civil servants who make up the European diplomatic corps.

\section{THEORIZING THE MAKING OF EU FOREIGN AND SECURITY POLICY IN PRACTICE}

The co-existence of continuity and contestation within the CFSP is a puzzle that defies the tenets of both the traditional EU integration theories as well as theories of social learning in international relations (IR). Among the classical integration theories (see Chapter 3), neofunctionalism posits that deepened integration is the result of spillover between policy areas, leading member states to push policy to the European level where the effects of integration between states can be managed. It also foresees an attendant shift of loyalty to a new political centre on behalf of both citizens and their representatives. Liberal intergovernmentalism, in turn, explains integration as the result of a mechanism of member states' preferences converging on the European level through a process of negotiation and trade-offs, raising the threshold for the lowest common denominator for policy positions on the European level. However, neither of these theories focus on the micro-level processes of reiterative policy-making that underpin the European foreign policy-making and produce output in terms of diplomatic action. As such, their attempts to explain the continuity of the CFSP tend to undervalue the experiences of those on the front line of EU foreign policy, that is, the practitioners of the CFSP.

In this book, we argue that by studying the diplomatic practices and patterns of interaction that have developed in the venues of coordination and 
implementation of the CFSP in the last decade, we can identify an important, albeit underestimated, dimension of integration: the management of contestation by member states' representatives and EU civil servants. As we will discuss further in Chapter 4, the iterative policy-making (coordination) creates practices, some as background knowledge of European diplomacy and some as patterns of reflexive behaviour. In the everyday making of European foreign policy, civil servants throughout the CFSP hierarchy who face preference divergence among the member states strive to make the CFSP work. That is, reaching consensus or overcoming institutional constraints often becomes more important than the substantial output of actions or policy. Our micro-level-based explanation is therefore more refined than the ones posited by either neofunctionalism or intergovernmentalism, as it is defined by the actions of practitioners without positing that their capacity to produce policy output depends on ideational convergence among the member states.

The existence of both continuity and contestation in the CFSP is also a puzzle for socialization theory and for the various approaches of practice theory. These theoretical frameworks aim to explain how individuals adopt and act on shared meanings. Similar to neofunctionalism, socialization theory assumes that individuals of a group who meet regularly to perform specific tasks should converge ideationally as a result of the repeated interaction and exposure to normative arguments. In this sense, socialization should eventually lead to normative suasion: the internalization of a group's norms as a result of successful persuasion. However, despite several decades of attempts to coordinate foreign policy within the EU, there is scant evidence of socialization in the form of normative suasion taking place among diplomats representing member states. This is partly a methodological issue, since it is hard, if not impossible, to measure norm internalization among individuals. More recent theoretical advancements in EU studies based on insights derived from practice approaches suggest that we should focus our analytical attention on what member state representatives actually do when they interact, rather than trying to capture the beliefs that (are assumed to) motivate actions. In particular, it is the non-reflective, taken-for-granted actions performed by individuals on an everyday basis that are of interest for scholars using practice approaches, as these actions hold promise to reveal the inarticulate knowledge of the field of European diplomacy and the practically derived dispositions of the individuals who operate therein. For these reasons, explaining an individual's actions as an outcome of norm internalization makes little sense from the perspective of practice. Instead, it is the innate sense of the boundaries of social practices in the field - a non-reflexive knowledge of what they can do, not what they should do - that predisposes individuals' actions in a particular social environment and which, interestingly, lead to path dependency and innovation. This is all the more important when we consider the institutional changes in EU 
foreign policy that have taken place since the 1990s, culminating in the setting up of the EEAS and a multitude of EU delegations in third countries where hundreds of EU officials carry out EU foreign policy on a daily basis.

Given the increasingly dense social interaction between diplomats based in Brussels and beyond, socialization theory would predict that contestation between member state representatives would decrease over time. As we show in Chapters 5 and 6, this is not the case. Moreover, diplomats are highly aware of this macro-level contestation and consciously formulate and implement policies that they know will work within the limited scope for action. The practical disposition to solve problems, seek compromises and muddle through, even though there are entrenched disagreements on substantive issues among member states, appears to be particularly pronounced among EU diplomats. The development of this attitude suggests that the management of contestation is becoming institutionalized within the CFSP. Although we do not know the effects this might have on the production of EU foreign policy in the future, it does call for a much closer scrutiny of how this community of diplomats manages contestation. Moreover, the extent to which this practice relies on non-reflexive and taken-for-granted actions needs to be studied rather than assumed. As neither socialization theory nor practice approaches by themselves can explain the complex development of contestation and continuity that we observe in EU foreign policy, we argue that it is necessary to combine the ontological positions of these two approaches to capture both what individuals think from (non-representational knowledge) as well as what they think about (representational knowledge). We believe this approach will allow us to better understand how specific practices of managing contestation have become institutionalized among CFSP practitioners.

Based on substantiated extensive empirical analyses of the above conditions, we make two main claims in this book: contestation and continuity occur simultaneously within the CFSP, and a theoretical lens is needed that can capture the practices and patterns of actions that allow practitioners to make EU diplomacy work (that is, a perspective that will reveal how the practitioners of EU foreign and security policy handle this apparent paradox of contestation and continuity in their everyday work). Subsequently, by combining insights from socialization theory regarding the different mechanisms through which individuals in a group learn the group's norms, with the insights from practice approaches regarding how, when and why individuals act on the basis of a shared practical knowledge, we can identify types of behaviour and processes of social learning that remain underspecified in these theoretical camps. In addition to contributing to the EU's literature and practices, this book contributes to the literature on the diffusion of diplomatic norms and practices in international institutions, which has become increasingly relevant in the context of the growing challenge to the liberal international order. In addition, 
Table $1.1 \quad$ Main aims of the volume

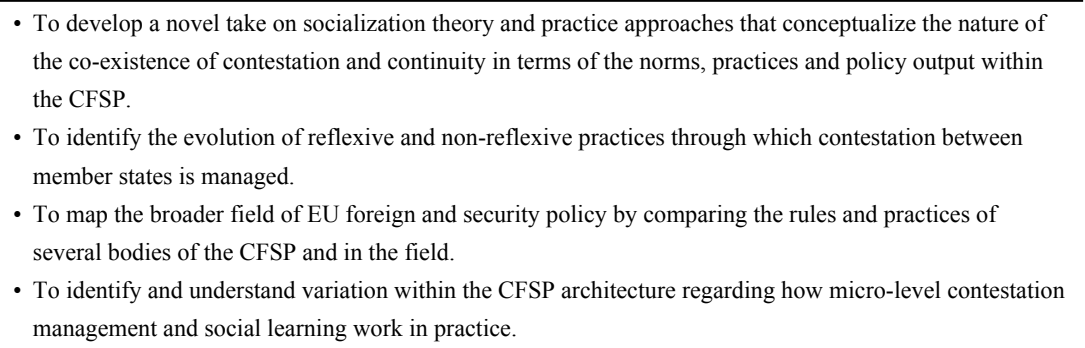

this book makes a distinct contribution to the study of diplomacy in order to better understand the emergence of transnational diplomatic communities of practice and the conditions - material as well as ideational - that define the patterns of interaction of European diplomats.

In parallel to conceptualizing the complexity of dissent and continuity through a combination of behaviour and practices, an additional key aim of the book is to identify the variation in social learning and contestation management across different levels and institutions of the CFSP and to understand how these practices are evolving; whether by design (formal rules) or through self-generating processes. For this reason, we focus on the practitioners within five key bodies of the CFSP: (1) the preparatory Working Groups of the Council of the European Union; (2) the Political and Security Committee (PSC); (3) the EEAS; (4) EU delegations and interaction with EU member state embassies; and (5) CSDP missions and operations. Therefore, the empirical cases vary both spatially and hierarchically, which impacts upon the emerging practices developed to manage macro-level contestation (see Chapters 5-9). The empirical chapters build on rich original data, including 79 semi-structured elite interviews with EU/EEAS diplomats and officials as well as member state representatives. The interviews were conducted between 2015 and 2021. ${ }^{1}$ This book also documents a time when EU foreign policy was coping with the disintegrating effects of Brexit and US abdication of global leadership under President Donald Trump. Table 1.1 summarizes the aims of the book as mentioned above.

1 One interview was conducted in December 2015, and the rest between 2016 and 2021. 


\section{DISPOSITION OF THE BOOK}

This book has two parts. In Part I, following this introductory chapter, we depict the historical development of cooperation in EU foreign and security policy (Chapter 2). A historical understanding of the emergence of EU foreign policy coordination reveals the long-standing patterns of consultation and cooperation that predate the codification of CFSP. These patterns include the practical knowledge of other EU member states' strategic culture as well as the diplomatic practices and traditions related to the habituation of working together in bodies and other venues instituted in the EU since the 1990s. Chapter 3 provides a different dimension of background knowledge of the EU foreign and security policy, in the form of theories of EU integration and international relations. Although the theories usually associated with explaining the EU have produced key concepts and theoretical tenets regarding the forces that drive integration, they have not analysed the individuals who through iterative interaction perform the practical actions towards the realization of EU foreign and security policy. Hence, there is a gap in our theoretical understanding about the habitus of the field of European diplomatic action that, although identified in social constructivist perspectives, remains only partially conceptualized. Therefore, in Chapter 4, we develop an analytical framework based on practice approaches and socialization theory to reveal practical knowledge and processes of learning and contestation in the everyday making of EU foreign and security policy. With this analytical framework, we provide theoretically informed accounts of stability and change of the norms, rules and procedures of those who interact on a daily basis in different venues to actualize and implement EU foreign and security policy.

In the Part II of the book, we move to the empirical case studies. In Chapter 5, we examine the role of the Council Working Groups (CWGs) - specifically, the Working Party on Eastern Europe and Central Asia (COEST) and the Politico-Military Group (PMG). Interestingly, these two groups have similar understandings of what constitutes a good diplomat; and both of them, despite their lower rank in the Council hierarchy, perceive themselves to be the main forums for the real negotiations on substantial issues that they are responsible for preparing. Moving up the hierarchical ladder, Chapter 6 puts the focus on the Political and Security Committee (PSC). In this committee, ambassador-level representatives of EU member states meet to prepare the agenda of the Foreign Affairs Council (the council configuration for ministers of foreign affairs). Despite a growing level of dissent in the group, the PSC has been able to uphold practices such as the norm of consensus-building and the coordination reflex. In Chapter 7, the focus is placed on the EEAS. The EEAS was created after intense institutionalization of EU foreign and security policy. 
Ten years after its inception, the EEAS staff still demonstrate fragmentation and multiple social identities. Nevertheless, officials are moved by a collective effort to fulfil the mission of the EEAS by learning how to work together and navigate the maze of formal and informal practices. In Chapter 8, the empirical focus moves outside the boundaries of Brussels to examine the role of EU delegations around the world, and the formal and informal practices that have emerged in the implementation of the CFSP. An important aspect of the implementation is the coordination with the EU member states' diplomatic missions, which have grown in importance. Even in the so-called bilateral capitals of Beijing and Washington, communities of practice are emerging among EU diplomats. Chapter 9 explores learning processes in the emergence of multiple communities of practice in the CSDP missions and operations around the world. Officials, often with a military background, have learned to work together and come to share understandings of what it means to enact EU foreign and security policy, while reflecting the cultures of cooperation in international security frameworks, most notably the United Nations and the North Atlantic Treaty Organization (NATO), where the EU also has a stake. Finally, in Chapter 10, the various strands of the theoretical perspective based on practice approaches and socialization are drawn together to assess the empirical findings at various venues at different bureaucratic levels of EU foreign and security policy. 